\title{
WISSENSCHAFT UND MESSKUNST
}

(Eine kleine Aphorismensammlung)

Gibt es denn kein Maß?

\section{Laudse \\ (Daudedsching)}

Wir sind zahlreichen Sinnestäuschungen ausgesetzt, und das beste Mittel dagegen ist das Messen, Zählen und Wägen.

$$
\text { Sokrates }(470-399 \text { v. u. Z. })
$$

Es ist nötig, alles zu messen, was meß̧bar ist, und zu versuchen, meßßbar zu machen, was es noch nicht ist.

$$
\text { Galilei (1564 - 1642) }
$$

Mancher suchet eyn pfenning und verbrinnt darbey drey lichte

$$
\text { Alte deutsche Spruchweisheit }
$$

Es ist der nackte, schneidende Verstand, der die Natur, die immer unfaßlich und in allen ihren Punkten ehrwürdig und unergründlich ist, schamlos ausgemessen haben will und mit einer Frechheit, die ich nicht begreife, seine Formeln, die oft nur leere Worte und immer nur enge Begriffe sind, zu ihrem Maßstabe macht.

Schiller

(Brief an Christian Gottlieb Körner vom 6. 8. 1797) 
Sein Bestreben, alles zu messen und zu anatomieren, gehört zur scharfen Beobachtung, und ohne diese gibt es keine brauchbaren Materialien für den Naturforscher.

\section{Christian Gottlieb Körner}

(Brief an Schiller vom 24. 8. 1799)

Bewährt den Forscher der Natur

ein frei und ruhig Schauen,

so folge Meßkunst seiner Spur

mit Vorsicht und Vertrauen.

Zwar mag in Einem Menschenkind

sich beides auch vereinen,

doch daß es zwei Gewerbe sind,

das läßt sich nicht verneinen.

Goethe

(Katzenpastete)

Daran erkenn ich den gelehrten Herrn!

Was ihr nicht tastet, steht euch meilenfern,

Was ihr nicht rechnet, glaubt ihr, sei nicht wahr,

Was ihr nicht wägt, hat für euch kein Gewicht,

Was ihr nicht münzt, das, meint ihr, gelte nicht.

Goethe

(Faust II)

Alles, was da ist, hat ein Maß.

Georg Wilhelm Friedrich Hegel

(Wissens chaft der Logik) 
Zählen und Messen sind die Grundlagen der fruchtbarsten, sichersten und genauesten wissenschaftlichen Methoden, die wir überhaupt kennen.

Hermann von Helmholtz

(Zählen und Messen)

Der Naturwissens chaftler weiß ja meistens wenig, er weiß unter andrem nicht, daß es gerade für die flüchtigen, beweglichen Werte, die er imponderabel nennt, außerhalb der Naturwissens chaft alte, hochkultivierte Meßund Ausdrucksmethoden gibt ...

Hermann Hesse

(Kurgast)

So formt uns unser Schicksal,

Die Welt der Daten und Ziffern um uns.

Doch nicht immer gerät

Nach Willen die Form

Dem Bläser. Oft in der Masse

Bläht es sich, daß sie

Zerspritzt, ihm versengend das Antlitz.

So hat auch ihre Grenze

Die Welt der Daten und Ziffern.

Lion Feuchtwanger

(Psalm vom Glasbläser in

"Der jüdis che Krieg")

Zahlen sind rein und schlüssig. Aber wer gibt mir Gewähr, daß auch das Leben aufgeht wie sie und nicht das Bekannte täuscht über das Unbekannte?

Thomas Mann

(Josef und seine Brüder, Bd. 2) 
Es gibt die erstaunliche Möglichkeit, daß man einen Gegenstand mathematisch beherrschen kann, ohne den Witz der Sache wirklich erfaßt zu haben.

\section{Albert Einstein \\ (Brief von 1950 an Max von Laue)}

Die Wissens chaft fängt eigentlich erst dort an, wo wir es mit Maßen, Gewichten und Berechnungen zu tun haben.

S. Strumilin

(Zur Methodologie der Berechnun-

gen der wissens chaftlichen Arbeit)

Der Kampf um die Meßbarkeit des Himmels ist gewonnen durch Zweifel.

Brecht

(Leben des Galilei)

Messen statt meinen.

Jürgen Kuczynski

(1962) 